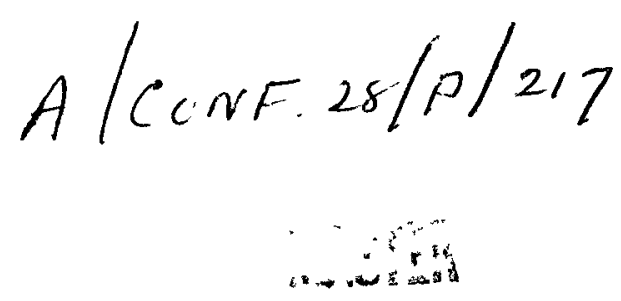

\title{
ISOTOPIC POWER SOURCES COUPLED WITH THERMOELECTRIC CONVERTERS
}

\author{
J. G. Morse, Manager and D. G. Harvey, Assistant Manager \\ Small Power Systems Department, Martin Company
}

Generation of electrical energy from the decay heat of radioisotopes has provided compact and reliable direct-conversion power sources capable of long-term, unattended operation. Feasibility of this technology was established under the USAEC SNAP (Systems for Nuclear Auxiliary Power) Program, which began in 1956 and led to the fabrication of a number of systems now providing dependable power for satellites in outer space, weather stations on land, and navigation buoys at sea [1].

This paper describes factors affecting the design of these power supplies and the status of technology in terms of performance specifications of systems in being or in design. Areas of technical growth required for broader use of these systems are also indicated.

1. Design Considerations

A thermoelectric generator, as shown in Fig. 1, consists of a sealed capsule of radioisotope fuel enclosed in a heat accumulator or metal block which provides sufficient surface on which to mount the thermoelectric converter. Thermal insulation is used to direct the heat efficiently from the fuel capsule to the converter with minimum heat leakage. Unconverted heat is rejected to the environment through the outer surface of the generator. The environment to which heat is rejected and the heat transfer technique used depend upon the end use of the power plant.

\section{Heat Source}

Since the driving thermal energy results from the absorption of radiations emanating from the encapsulated radioisotope, proper selection of the fuel and its containment are basic to the design of the device. Half-life must be compatible with mission objectives; high power density (watts per cubic centimeter) is necessary to minimize size and weight; the type of radiations from the source and its daughters in secular equilibrium will dictate shielding requirements consistent with the foregoing criteria; chemical 


\section{DISCLAIMER}

This report was prepared as an account of work sponsored by an agency of the United States Government. Neither the United States Government nor any agency Thereof, nor any of their employees, makes any warranty, express or implied, or assumes any legal liability or responsibility for the accuracy, completeness, or usefulness of any information, apparatus, product, or process disclosed, or represents that its use would not infringe privately owned rights. Reference herein to any specific commercial product, process, or service by trade name, trademark, manufacturer, or otherwise does not necessarily constitute or imply its endorsement, recommendation, or favoring by the United States Government or any agency thereof. The views and opinions of authors expressed herein do not necessarily state or reflect those of the United States Government or any agency thereof. 


\section{DISCLAIMER}

Portions of this document may be illegible in electronic image products. Images are produced from the best available original document. 
form of fuel must satisfy safety requirements; cost and availability must also be consistent with the mission needs.

Fuels are obtained by purifying fission products or irradiating suitable target materials. Fissioning of uranium yields several hundred radioisotopes--of these, only four radionuclides are applicable to power generators. These are identified in Table I. Several predictions of quantities of fission wastes in a growing reactor economy have been made. One such estimate for strontium-90(Sr-90) suggests 1 billion curies or 5 megawatts of thermal power by 1980 , indicating large quantities of fuel materials for remote power applications [2].

The second source of fuels provides alpha-emitting radioisotopes which are particularly important for certain missions where little or no radiation or shielding weights can be tolerated. The problems of shielding isotopic power sources for space missions are covered in Ref. 3.

Certain alpha-emitters undergo spontaneous fission and also enter into alpha-neutron reactions when combined with elements of low atomic number $[3,4]$. They are perforce more costly than fission products; and because of this, various fuel forms of strontium90 are under active development for space missions. This radionuclide has already demonstrated its utility in terrestrial applications.

\section{Fuel Encapsulation}

The quantities of fuel required for power generation normally represent a radioisotope inventory of considerable size, and would cause a significant hazard if improperly released to the biosphere. Absolute containment of the fuel, therefore, must be assured until decay has rendered the isotope harmless. Space generators use multiwalled cobalt or nickel-base superalloys in cylindrical geometry with welded end closures. Such capsules, with simulated fuel, have been extensively tested and found to satisfy the stringent containment requirement for aborted missions. Fire and explosion of the vehicle on the launching pad $\left(3200^{\circ} \mathrm{C}\right.$ for microseconds, falling off rapidly to $900^{\circ}$ to $1600^{\circ} \mathrm{C}$--integrated thermal fluxes produced will not melt the capsule or release fuel); blast overpressures (700 atm. will not breach the fuel housing and will not result in release of the fuel); high velocity impact against granite targets at operating temperatures to duplicate the environment of an ascent abort show that the fuel remains contained within the capsule. Testing has also assured containment of fuel when the capsule is subjected to high internal pressures. This was necessary since alpha-emitters such as $\mathrm{Pu}-238$, Po-210, etc., release helium atoms upon decay $[5]$.

Terrestrial systems have relied on Hastelloy-C, a nickel-base alloy, for primary containment. Tests have shown that the rate of sea water corrosion of this material is 
less than $0.00025 \mathrm{~cm}$. per year. Suitable wall thicknesses will provide containment in an ocean environment for more than 20 half-lives of Sr-90.

\section{Energy Conversion}

The phenomenon of thermoelectricity was described first by Seebeck in 1832, who noticed that a temperature difference imposed across a junction of two dissimilar metals will generate an electrical potential[6]. Intensive investigations to develop suitable semiconductor materials for this end use have yielded $\mathrm{Bi}_{2} \mathrm{Te}_{3}, \mathrm{PbSnTe}, \mathrm{GeSi}$, and a few others, each with its attendant advantages and disadvantages. The conversion efficiency is directly related to the Carnot efficiency and to the figure of merit (Z), a term that is dependent upon both materials properties and temperature $[7]$.

$$
\mathrm{Z}=\frac{\alpha^{2}}{\rho \mathrm{K}}
$$

where:

$$
\begin{array}{lc}
\mathrm{Z}=\text { Figure of merit }\left({ }^{\circ} \mathrm{C}\right)^{-1} & \rho=\text { Electrical resistivity (ohm-centimeters) } \\
\alpha=\text { Seebeck coefficient (volts) }\left(^{\circ} \mathrm{C}\right)^{-1} & \mathrm{~K}=\begin{array}{c}
\text { Thermal conductivity (watts) }\left({ }^{\circ} \mathrm{C}\right)^{-1} \\
\text { (centimeters) }
\end{array}
\end{array}
$$

ZT, a dimensionless number, is plotted in Figs. 2 and 3 for these materials in both $\mathrm{N}$ and $\mathrm{P}$ doping conditions. For maximum conversion efficiency, materials are selected for highest average values over the temperature range determined by the boundary conditions; namely, heat source and radiator temperatures. Space systems will require higher radiator temperatures than terrestrial systems, to economize on weight and size. Higher power-to-weight ratios are obtained, however, at the expense of efficiency $[7]$.

Figure 4 illustrates the typical characteristics of a thermoelectric generator, all of which are predictable on the basis of simple theory. The generator behaves as a voltage source and, when connected in series with a resistor, yields maximum power at a given point of matched impedance. The power curve for a given generator is obtained by first measuring variation of voltage with current from short to open circuit under conditions of steady-state performance. Peltier cooling will affect the hot-side temperature slightly. This temperature is at a maximum under conditions of zero current, since none of the heat is converted into electricity; it is lowest at short circuit where maximum Peltier cooling occurs. The nonlinearity in the E-I curve is due to material property dependence on temperature. The internal resistance curve also reflects this nonlinearity. Open circuit voltage, as well as the short circuit condition, can be computed from the Seebeck voltage and the temperature range of operation. All other properties can be determined from temperature range and property data. 
These characteristics show how the radioisotope thermoelectric generator may be used most effectively. The nature of the power curve indicates that the system is ideal for conditions of constant, continuous power. It will not, however, tolerate significant deviations in load voltage from the maximum power point. In addition, it makes an excellent battery charger, in that its voltage will follow that of the battery and will trickle charge without boiling off the electrolyte. This provides a technique for furnishing power to systems requiring high peak power on a partial duty cycle.

A further characteristic is that it is a high-current, low-voltage device requiring series (or series-parallel) connections within each bank of thermocouple pairs to increase the overall voltage. To match the electrical characteristics of the power slipply to the requirements of the payload, a static, solid-state, dc-to-dc converter is often used. These have operated at efficiencies of up to $92 \%$ between 3 and 30 volts. The efficiency is largely dependent on the degree of regulation required.

\section{Power Flattening}

Unique with radioisotope power technology is the reduction of thermal input power with time as the fuel decays. With radioisotopes of short half-life, such as Po-210, $\mathrm{Cm}-242$, etc., a controllable thermal bypass is introduced around the thermoelectric elements to maintain a constant hot-side temperature over the mission life. In SNAP 11, a thermal shutter exposed the fuel capsule to space at the beginning of life. Figure 5 shows shutter actuation accomplished by means of a thermal sensing device operating by the expansion of a liquid metal. The SNAP 7 series uses a thermally conductive gas, which may be replaced by a less conductive gas after an interval of several years to ralse the hot-side temperature to approximately its initial value. However, with generators fueled with long-lived isotopes such as $\mathrm{Pu}-238$ or $\mathrm{Sr}-90$, a small initial overload of inventory and operation below the maximum power point on the curve in Fig. 5 will provide essentially constant power for a 10-year period.

\section{Generator Safety}

An extensive discussion of generator safety is given in Ref. 10. Although reliance is placed first on fuel containment, generator systems are tested against environmental criteria basic to their end use. These include thermal and mechanical shock and vibration peculiar to the mission. Terrestrial generators have been fueled with strontium-90 titanate, a chemical compound that has demonstrated extremely low solubility in fresh and sea water [8]; good thermal conductivity; a melting point that is at least a factor of two higher than the centerline temperature of the fuel capsule within the operating generator; and no decomposition on melting. These generators are fully shielded, using depleted uranium to attenuate the radiation flux to less than 10 millirads per hour at one meter from centerline. 
The design of space generators must reflect the ultimate fate of the nuclear fuel. Under conditions of uncontrolled re-entry from earth orbit, burnup of the fuel to micronsize particles must occur at altitudes greater than 30,480 meters to achieve dispersal in the stratosphere. However, the orbit selected for SNAP 9A reflects a lifetime that is equal to about 10 half-lives of $\mathrm{Pu}-238$. Extensive laboratory and flight test programs prior to meeting mission requirements have demonstrated the sound technical basis for satisfying this philosophy. Alpha-emitters could conceivably be designed to re-enter intact, recognizing the weight penalty required for the ablator or heat shield materials $[9]$.

Launch trajectories are analyzed carefully to determine the region of impact in the much less probable event of partial burnup. Launch azimuths are selected with care to confine these regions to ocean areas of essentially zero population density $[10]$.

\section{Operational Systems}

With the launching of the modified SNAP 3 and SNAP 9A systems, illustrated in Fig. 6 , the first use of nuclear power in space was achieved. The initial satellite was orbited in June 1961. Although the first units shared the power load with companion solar cells, after less than a year of operation, the SNAP system was the only source of power. It continues to provide power at this time. The second, launched in November 1961, failed suddenly six months later. Analyses of telemetry data indicate the failure to be external to the generator. The SNAP 9A systems are providing design power to the load.

Projects IMP (Interplanetary Monitoring Probe), Nimbus, Surveyor, and ComSat (Communications Satellite) will use advanced generator technology to provide higher performance systems. ComSat anticipates using Sr-90, which will necessitate further safety development, particularly the ability to handle the fission product at the launching pad with minimum perturbations during the countdown procedures. Data on these systems are listed in Table $I$.

The first operational terrestrial system to use radioisotope power is seen in Fig. 7 . It sensed and transmitted weather data at three-hour intervals in an unattended, remote Arctic weather station for more than two years [11]. After exceeding its design life by several months, a failure in the electronics system required dismantling the station. The generator is awaiting re-installation this summer, with electronics equipment commensurate with the inherent reliability of the generator. The SNAP 7 series, as noted in Table III, represents improvement in power and design over the earlier device. Modularization of the thermoelectric elements has contributed markedly to the ease of assembly. Advanced systems will employ internally shielded thermoelement modules 
and more efficient thermal insulation, yielding lighter and higher performance devices.

Advanced development will focus on improved thermoelectric materials, as well as more effective use of existing materials. The latter relates to Figs. 2 and 3 , in which the most effective use of the compositions noted is restricted to a narrow portion of the temperature range. At present, thermoelectric configurations in operational systems are composed of $\mathbf{P}$ and $\mathbf{N}$ legs of a single composition. Significant advantages will accrue when elements are constructed as composite materials, operating over a wider temperature range. A temperature profile along the axis of such an element would indicate the transition of one material to another, corresponding to the intersections of their ZT curves. The highest average ZT for each material would be obtained, thus maximizing the potential efficiency. Although values of about $20 \%$ are theoretically possible, practical considerations, such as heat sink, source temperature, and thermal leakage for a given application will tend to reduce this value. Other such factors as material interface problems, compatibility, etc., will likewise impose limitations; but the approach is nonetheless worthy of intensive investigation.

Further considerations for technological improvement will include efficient high temperature thermal insulation, heat source, cladding, and encapsulation materials, all of which will provide a basis for the designing of truly advanced generators.

\section{Conclusions}

The advantages of isotope power sources are many. They are compact, light in weight, without moving parts, and reliable for a long term. In space, these systems are completely independent of the sun, eliminating the need for reliance on vehicle placement, orientation, and complex solar acquisition mechanisms. They are insensitive to radiation belts, and they obviate the need for energy storage in batteries. They lend themselves to long-lived satellites and to lunar and planetary probes exploring environments and surfaces where reliability is a major consideration. Their useful power range extends to the low kilowatt region, offering a power capability to satisfy a number of manned mission requirements.

Terrestrial systems have demonstrated continuous, reliable performance which recommends their use in barren, inaccessible places for unattended applications. These have already included automatic weather in polar regions and at sea, navigation aids, and ocean-bottom signal devices. A barge weather station, using SNAP 7D, is seen in Fig. 8. These applications will soon encompass networks of remote weather stations providing data to computation centers, radio-navigation aids for aircraft, telephone repeater power supplies, and precise, undersea markers for shipping and transportation. 
The growth in usage of radioisotope power systems has developed with caution and responsibility, with respect for the inherently hazardous nature of the materials themselves. Each mission was adjudged to be safe only after extensive testing peculiar to the mission profile; this effort will continue for each operational system.

Although the cost of fuel materials is the dominant factor in the cost of the power supply, it is more often a smaller factor in the overall mission cost, particularly in space, where long-term reliability and low weight must be considered along with other ways of providing power. Terrestrial radioisotope units reduce considerably the logistics of resupply and will be truly competitive when (a) the equipment requiring power has both life and reliability compatible with those of the power source, and (b) fission products become available in massive quantities from the now planned USAEC production facility $[1]$.

Radioisotope fueled thermoelectric generators have already shown, and continue to demonstrate, their utility and practicability to provide reliable, long-term power for missions involving all regions of earth and outer space.

\section{Bibliography}

[1] STEWART, D. H., ANDERSON, G. M., JORDY, G. Y., and WEINER, M., "An Evaluation of Systems for Nuclear Auxiliary Power," TID-20079 (1964).

[-2] BELTER, W. G., Intern. Sci. Technol., No. 12 (1962) 42.

[3] NICHOLS, J. P., and ARNOLD, E. D., "Shielding Isotopic Power Sources for Space Missions," Nucleonics 22, No. 2 (1964) 52.

[4] SEABORG, G. T., "The Transuranium Elements," Nuclear Science and Engineering, 9, No. 4 (1961) 475 .

[5] MORSE, J. G., "Radionuclide Power Sources," J. of the Brit. Interplanetary Soc., 19, No. 3 (1962) 87.

[6] JOFFE, A. F., "Semiconductor Thermoelements and Thermoelectric Cooling," Infosearch, Ltd. (1957).

[7] PSAROUTHAKIS, J. and STREB, A. J., "Radioisotope Space Power," XIV International Astronautic Congress, Paris, September 1963.

[8] BLOOM, J. L. and RIGGS, C. O., "Significance of Solubility Data in Determining Rates of Solution and Diffusion of Strontium-90 in the Form of Strontium Titanate," Health Physics Soc. Annual Meeting, Chicago, June 1962. 
[9] SCHULMAN, F., "Generator Performance and Mission Prospects," Nucleonics 21 , No. 9 (1963) 54-58.

[10] HARVEY, D. G., DICK, P. J., and FINK, C.R., "Isotope Generator Reliability and Safety," Nucleonics 21, No. 4 (1963) 56.

[11] MORSE, J. G., "Energy for Remote Areas," Science 139, No. 3560 (1963) 1175-1180. 


\section{TABLE I}

Properties of Radioisotopes

\begin{tabular}{|c|c|c|c|c|c|c|c|c|}
\hline \multirow{2}{*}{$\frac{\text { Nuclide }}{\text { Chemical Form }}$} & \multirow[b]{2}{*}{$\begin{array}{l}\text { Type of } \\
\text { Decay }\end{array}$} & \multirow[b]{2}{*}{$\begin{array}{l}\text { Half- } \\
\text { Life }\end{array}$} & \multirow[b]{2}{*}{ (watts/gram) } & $\begin{array}{c}\text { Specific Activity } \\
\text { (thermal) }\end{array}$ & \multirow[b]{2}{*}{ (curies/watt) } & \multicolumn{3}{|c|}{ (megacuries/year) $^{(\text {a) }}$} \\
\hline & & & & (watts $\left./ \mathrm{cm}^{3}\right)$ & & $\underline{1964}$ & $\underline{1970}$ & $\underline{1980}$ \\
\hline $\mathrm{Sr}^{90} \mathrm{TiO}_{3}$ & $\boldsymbol{\beta}$ & 27.7 years & 0.21 & 0.7 & 154 & 3 & 25 & 100 \\
\hline $\mathrm{Cs}^{137}$ (glass) & $\beta, \gamma$ & 27 years & 0.072 & 0.215 & 210 & 1 & 25 & 100 \\
\hline $\mathrm{Pm}_{2}^{147} \mathrm{O}_{3}$ & $\boldsymbol{\beta}$ & 2.6 years & 0.18 & 1.0 & 2700 & 0.1 & 50 & 150 \\
\hline $\mathrm{Ce}^{1+4} \mathrm{O}_{2}$ & $\beta, \gamma$ & 285 days & 2.3 & 13.8 & 128 & 1 & 200 & 4000 \\
\hline $\mathrm{Po}^{210}$ (metal) & $\alpha^{(b)}$ & 138 days & 140 & 1320 & 31.6 & 0.1 & 3 & 30 \\
\hline $\mathrm{Cmi}_{2}^{242} \mathrm{O}_{3}$ & $\alpha$ & 162 days & 120 & 1170 & 27.6 & 0.06 & 0.3 & \\
\hline $\mathrm{Cm}_{2}^{244} \mathrm{O}_{3}$ & $\alpha$ & 18 years & 2.5 & 22.5 & 28.6 & & $0.2^{(\mathrm{c})}$ & \\
\hline $\mathrm{Pu}^{238}$ (metal) & $\boldsymbol{a}$ & 90 years & 0.48 & 9.3 & 29.0 & 0.1 & 0.6 & 1.5 \\
\hline $\begin{array}{l}\therefore \text { EC Isotop } \\
\text { Medicine } \mathrm{m}\end{array}$ & $\begin{array}{l}\text { uels Prog } \\
\text { ng, 30 Jar }\end{array}$ & $\begin{array}{l}\text { m, division o } \\
\text { ry } 1964 .\end{array}$ & topes Develor & ent. Presentati & $\mathrm{n}$ by W. K. Eist & to $\mathrm{Chi}$ & go Biol & and \\
\hline Gamma abu & ace is 0.0 & Bt $0.8 \mathrm{Mev}$. & & & & & & \\
\hline
\end{tabular}




\section{TABLE II}

Space Thermoelectric Generator Specifications

\begin{tabular}{|c|c|c|c|c|c|c|c|c|c|c|c|c|}
\hline \multirow[b]{2}{*}{ Generator } & \multirow{2}{*}{ 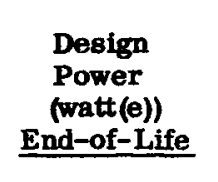 } & \multirow[b]{2}{*}{$\begin{array}{c}\text { Design } \\
\text { Life } \\
\text { (years) } \\
\end{array}$} & \multirow[b]{2}{*}{ Fuel } & \multicolumn{3}{|c|}{ End-of-Life Output } & \multicolumn{2}{|c|}{ Radiator Surface } & \multicolumn{2}{|c|}{ Configuration } & \multirow[b]{2}{*}{$\begin{array}{c}\text { Operation } \\
\text { Date } \\
\end{array}$} & \multirow[b]{2}{*}{ Mission } \\
\hline & & & & $\begin{array}{l}\text { Voltage } \\
\text { (volts) }\end{array}$ & $\begin{array}{c}\text { Current } \\
\text { (amperes) }\end{array}$ & $\begin{array}{c}\text { External } \\
\text { Load } \\
\text { (ohms) } \\
\end{array}$ & $\begin{array}{l}\text { Fins } \\
\left(\mathrm{m}^{2}\right)\end{array}$ & $\begin{array}{l}\text { Housing } \\
\left(\mathrm{m}^{2}\right) \\
\end{array}$ & $\begin{array}{l}\text { Length } \\
\text { (cm) }\end{array}$ & $\begin{array}{c}\text { Diameter } \\
(\mathrm{cm}) \\
\end{array}$ & & \\
\hline $\begin{array}{l}\text { Modified } \\
\text { SNAP } 3\end{array}$ & 2.7 & 5 & Pu-238 & 2.7 & 1.0 & 3.0 & None & 0.055 & 13.97 & 12.19 & 1961 & DOD satellite \\
\hline SNAP 9A & 25.0 & 6 & $\mathrm{Pu}-238$ & 6.4 & 4.6 & 2.0 & 0.193 & 0.154 & 24.13 & 50.80 & 1963 & DOD satellite \\
\hline SNAP 11 & $18.6^{(a)} / 25^{(b)}$ & $1 / 4$ & $\mathrm{Cm}-242$ & 3.0 & 8.33 & 0.42 & 0.093 & 0.151 & 27.94 & 45.72 & 1965 & Surveyor \\
\hline SNAP 17 & 25.0 & 5 & Sr-90 & 6.6 & 3.8 & 1.75 & 0.121 & 0.140 & 31.75 & 16.76 & 1965 & $\begin{array}{l}\text { Communication } \\
\text { satellite }\end{array}$ \\
\hline SNAP 19 & 22.0 & 3 & Pu-238 & 4.75 & 4.65 & 1.02 & 0.095 & 0.094 & 24.76 & 13.56 & 1965 & $\begin{array}{l}\text { Interplanetary } \\
\text { monitoring }\end{array}$ \\
\hline Undesignated & $6-10$ & $>1$ & $\begin{array}{l}\mathrm{Pu}-238 \\
\text { or } \mathrm{Sr}-90\end{array}$ & -- & -- & -- & - & -- & -- & - & -- & $\begin{array}{l}\text { Lightweight } \\
\text { demonstration } \\
\text { device }\end{array}$ \\
\hline
\end{tabular}

(a) Lunar day

(b) Lunar night 


\section{TABLE III}

Terrestrial Thermoelectric Generator Specifications

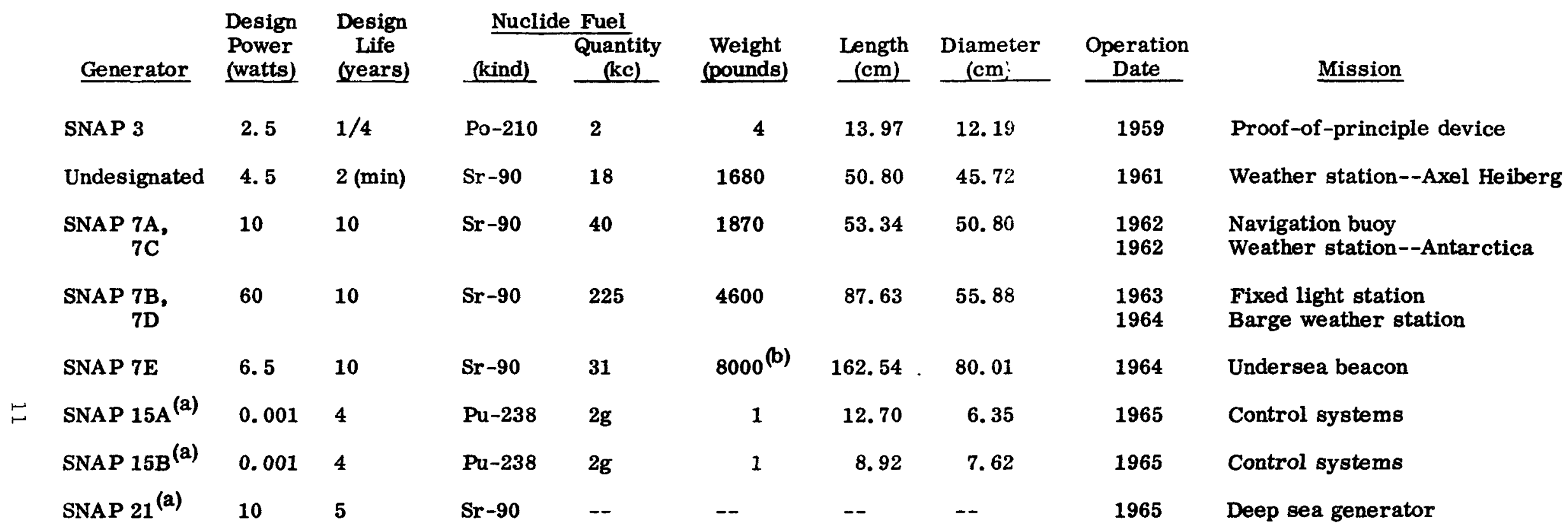

(b) Special pressure vessel for deep ocean mooring 


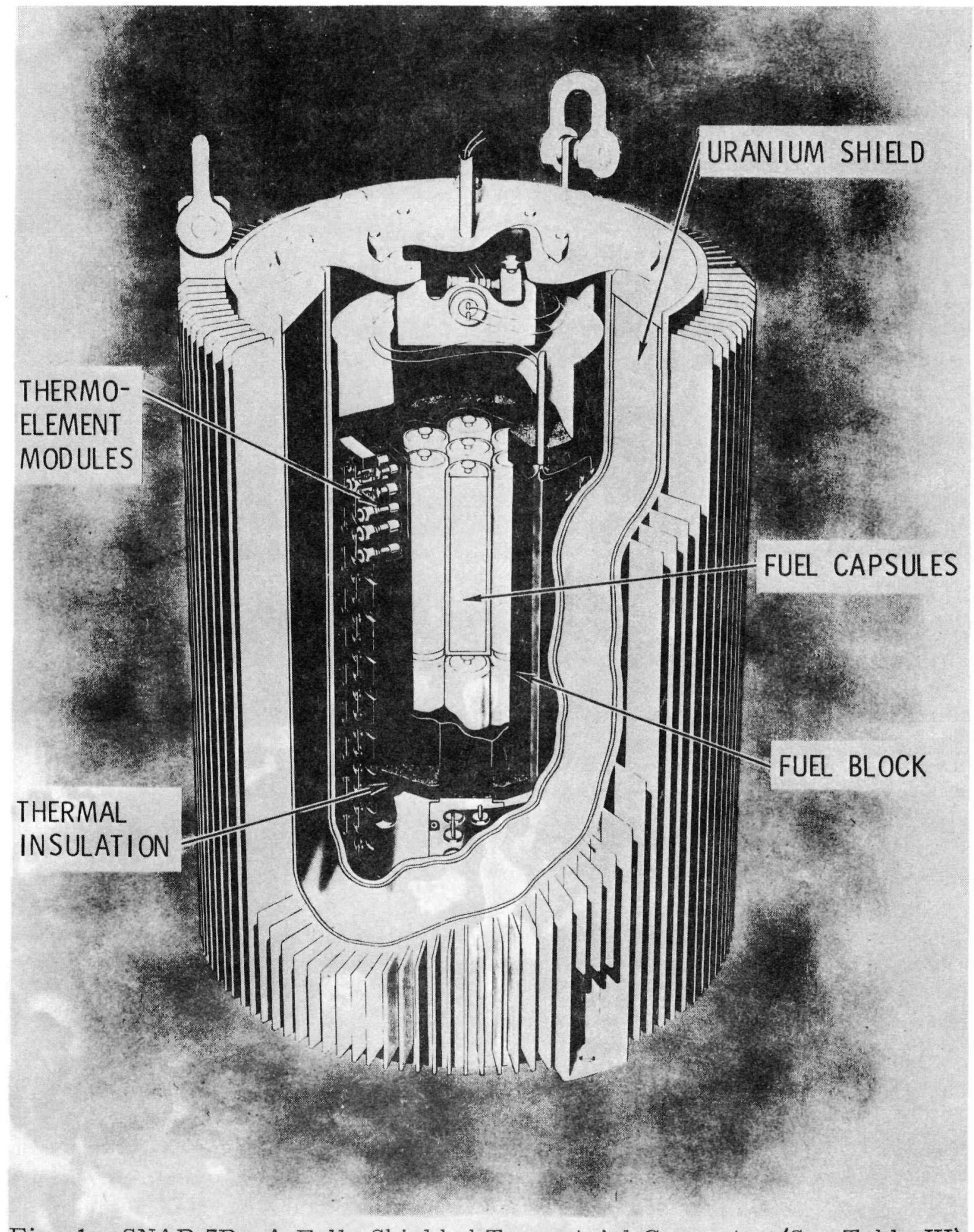

Fig. 1. SNAP 7B--A Fully Shielded Terrestrial Generator (See Table III) 
"Isotopic Power Sources Coupled with Thermoelectric Converters," by J. G. Morse and D. G. Harvey.

Fig. 1. SNAP 7B--A Fully Shielded Terrestrial Generator (see Table III). 


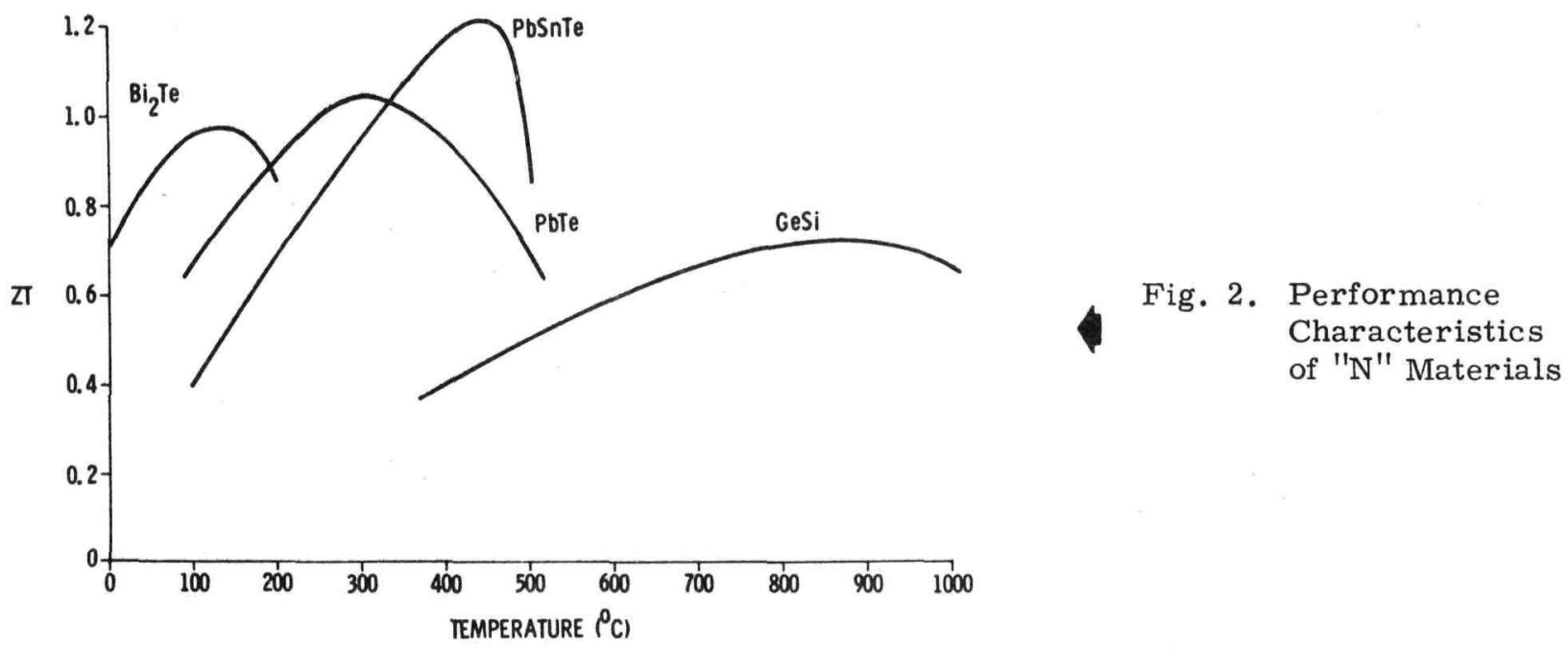

Fig. 3. Performance Characteristics of "P" Materials
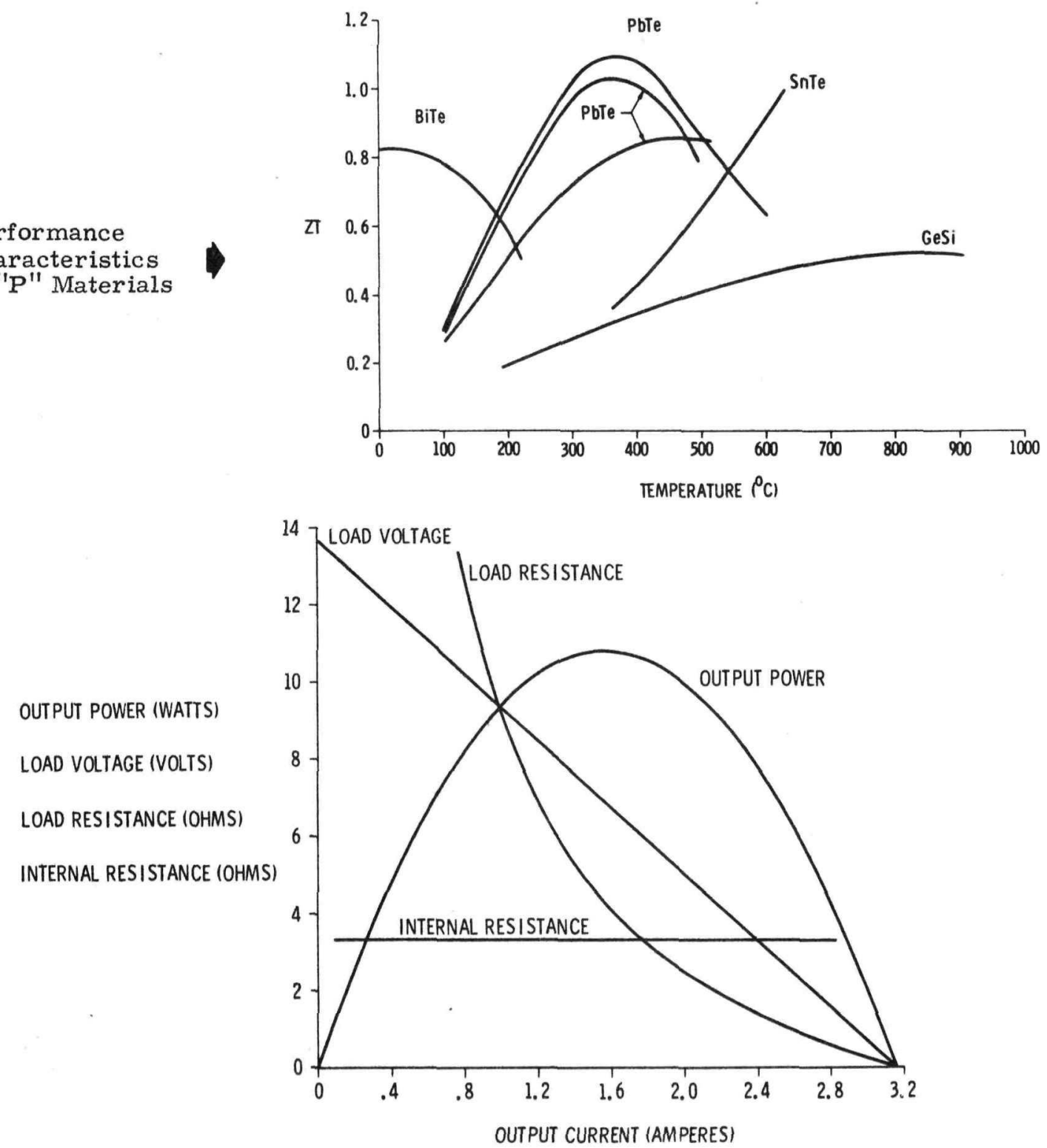

Fig. 4. Electrical Characteristics of a Thermoelectric Generator 
"Isotopic Power Sources Coupled with Thermoelectric Converters," by J. G. Morse and D. G. Harvey.

Fig. 2. Performance Characteristics of "N" Materials.

Fig. 3. Performance Characteristics of "P" Materials.

Fig. 4. E1ectrical Characteristics of a Thermoelectric Generator. 


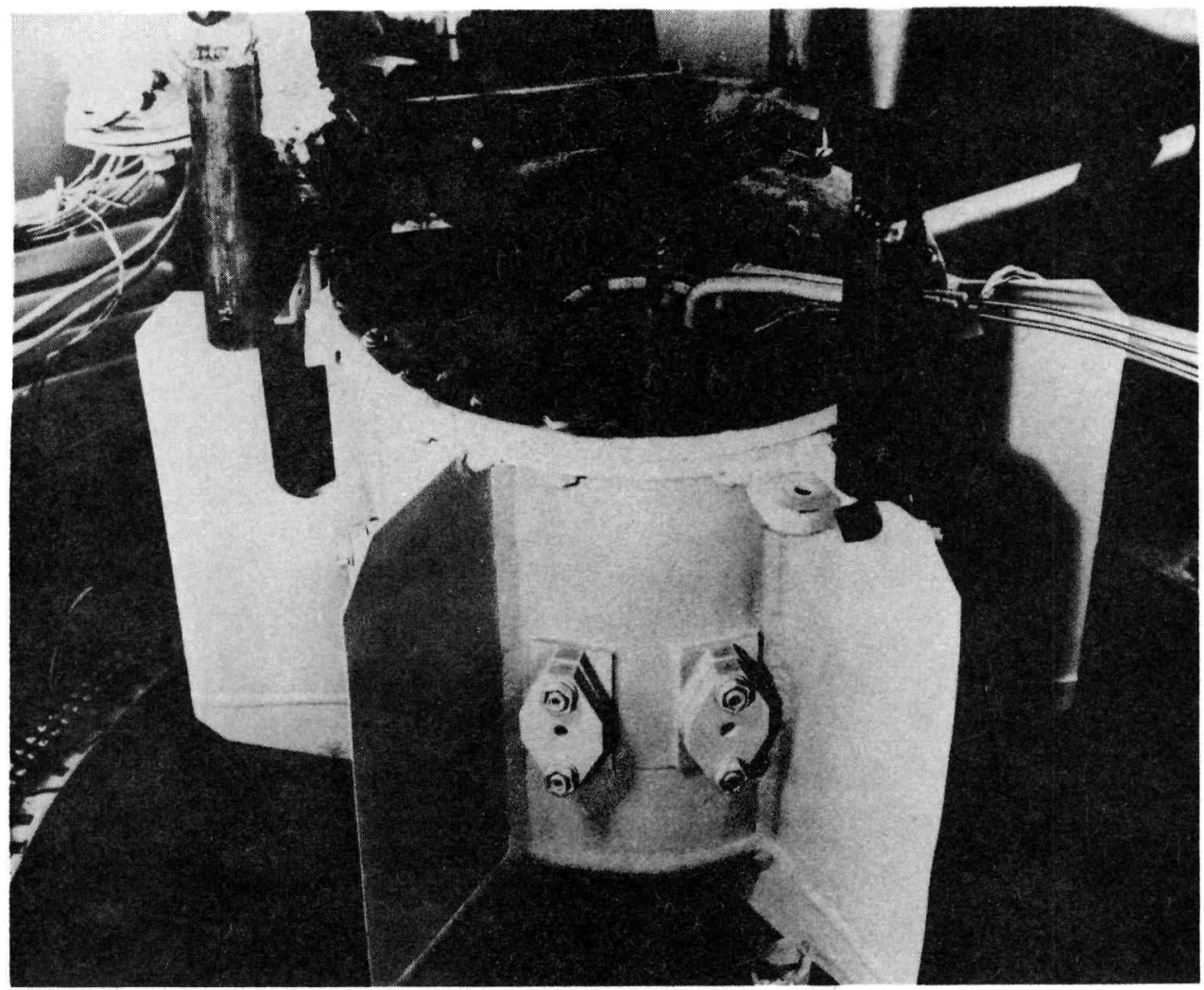

Fig. 5. SNAP 11 Test Unit, Showing Thermal Shutter

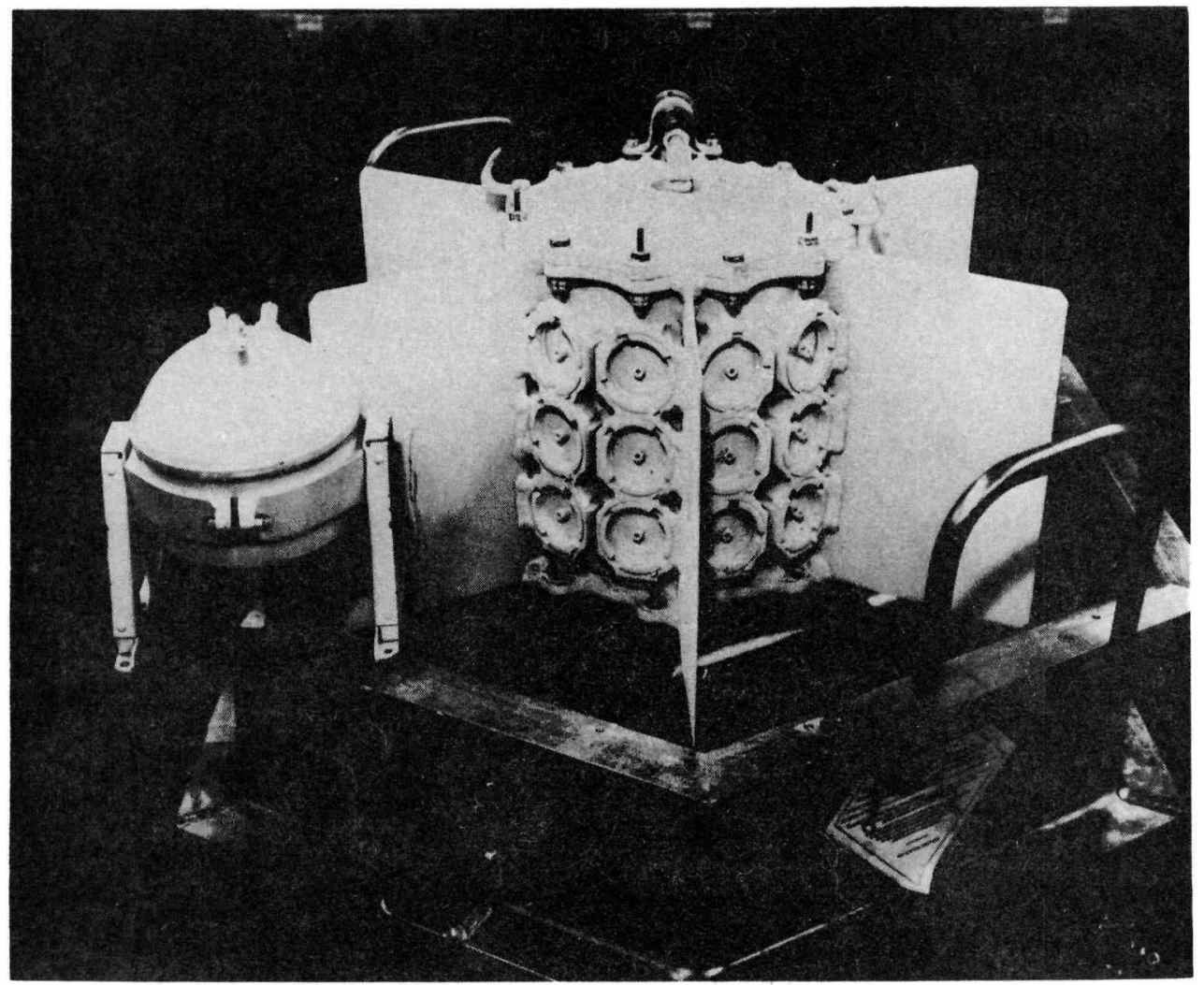

Fig. 6. First Nuclear Power Plant in Space.

(Modified SNAP 3 on left; SNAP 9A on right) 
"Isotopic Power Sources Coupled with Thermoelectric Converters," by J. G. Morse and D. G. Harvey.

Fig. 5. SNAP 11 Test Unit, Showing Thermal Shutter.

Fig. 6. First Nuclear Power Plant in Space. (Modified SNAP 3 on 1eft; SNAP 9A on right) 


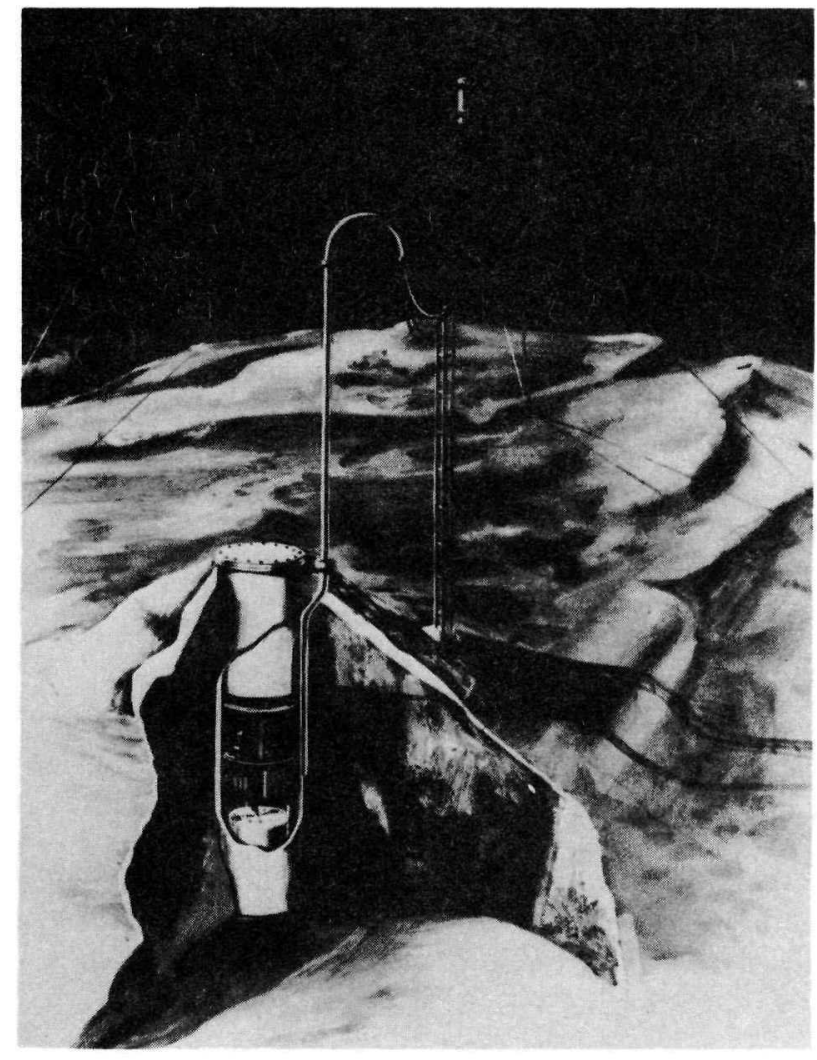

Fig. 7. Axel Heiberg Weather Station-Artist's Concept

Fig. 8. SNAP 7D-Powered Weather Barge in Gulf of Mexico

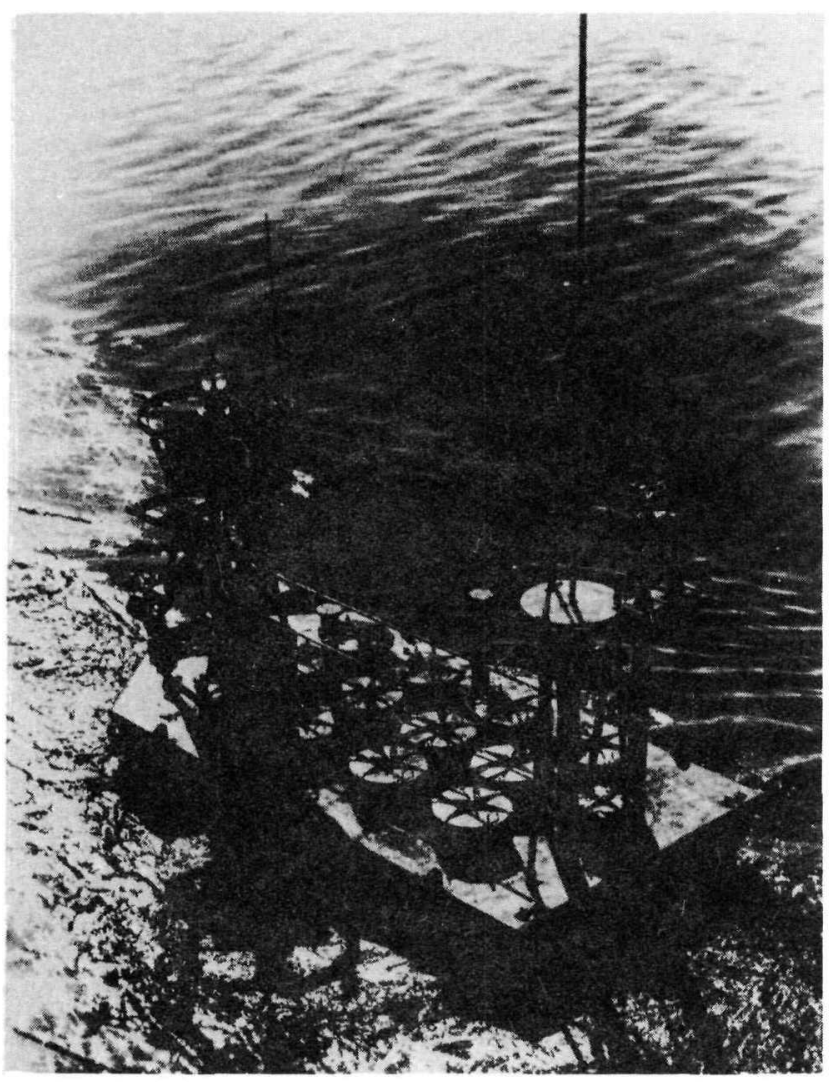


"Isotopic Power Sources Coupled with Thermoelectric Converters," by J. G. Morse and D. G. Harvey.

Fig. 7. Axel Heiberg Weather Station--Artist's Concept.

Fig. 8. SNAP 7D-Powered Weather Barge in Gulf of Mexico. 
"Isotopic Power Sources Coupled with Thermoelectric Converters," by J. G. Morse and D. G. Harvey.

\section{FIGURE CAPTIONS}

Fig. 1. SNAP 7B--A Fully Shielded Terrestrial Generator (see Table III). Fig. 2. Performance Characteristics of "N" Materials.

Fig. 3. Performance Characteristics of "P" Materials.

Fig. 4. Electrical Characterstics of a Thermoelectric Generator.

Fig. 5. SNAP 11 Test Unit, Showing Thermal Shutter.

Fig. 6. First Nuclear Power Plant in Space. (Modified SNAP 3 on left; SNAP 9A on right)

Fig. 7. Axe1 Heiberg Weather Station--Artist's Concept.

Fig. 8. SNAP 7D-Powered Weather Barge in Gulf of Mexico. 


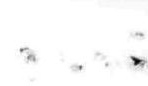

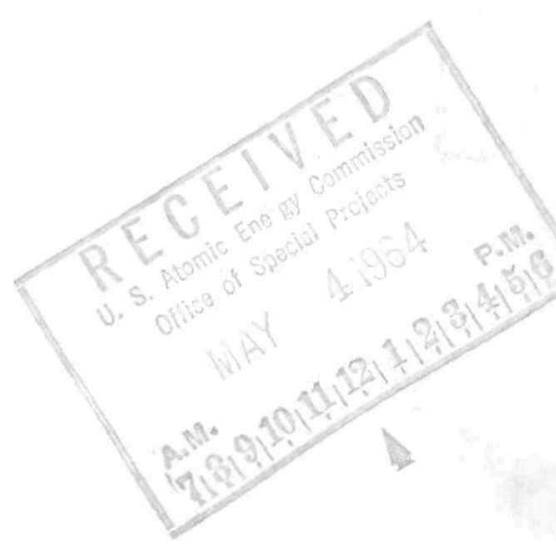

